\title{
Erratum to: Sub-chronic exposure to low concentration of dibutyl phthalate affects anthropometric parameters and markers of obesity in rats
}

\author{
Khalid Abdul Majeed $^{1} \cdot$ Habib ur Rehman ${ }^{1} \cdot$ Muhammad Shahbaz Yousaf $^{1}$ • \\ Hafsa Zaneb ${ }^{2} \cdot$ Imtiaz Rabbani $^{1} \cdot$ Sajid Khan Tahir ${ }^{1} \cdot$ Muhammad Afzal Rashid $^{3}$
}

Published online: 5 October 2017

(C) Springer-Verlag GmbH Germany 2017

Erratum to: Environ Sci Pollut Res

https://doi.org/10.1007/s11356-017-9952-y

The correct name of the 1st and corresponding Author is Khalid Abdul Majeed.

The original article was corrected.

The online version of the original article can be found at https://oi.org/ $10.1007 / \mathrm{s} 11356-017-9952-\mathrm{y}$

Khalid Abdul Majeed

Khalid.majeed@uvas.edu.pk; http://www.uvas.edu.pk/academics/

faculties/fbs/physiology/faculty/staff/majeed.htm

1 Department of Physiology, University of Veterinary and Animal Sciences, Outfall Road, Lahore 54600, Pakistan

2 Department of Anatomy and Histology, University of Veterinary and Animal Sciences, Lahore 54600, Pakistan

3 Department of Animal Nutrition, University of Veterinary and Animal Sciences, Lahore 54600, Pakistan 